'neither reliable nor important' (an educated finger on the carotid can usually differentiate aortic sclerosis and stenosis); systolic murmurs are 'unlikely to be important' if they vary with posture, are not associated with symptoms or cardiomegaly and if the chest X-ray is normal (what about maladie de Roger, mitral valve prolapse and bicuspid aortic valve?).

The pictures are excellent and the price reasonable. Many students will learn from this book but it lacks references and they will need a more traditional text to look things up.

M. Petch

Papworth Hospital,

Cambridge CB3 8RE

\section{Diagnosis and Management of Acute Poisoning. Diagnosis and Management Series}

By Alexander T. Proudfoot. Pp. viii + 237. Blackwell Scientific Publications, Oxford, London, Edinburgh, Boston, Melbourne, 1982. $£ 7.50$.

Diagnosis and Management of Acute Poisoning admirably fulfils the objective of its author in giving highly practical help to junior doctors who are dealing with a poisoning problem. Having classified the types of poisoning; Dr Proudfoot then deals thoroughly with diagnosis and treatment. At the end of each section the salient points are concisely emphasized and these summaries alone would be of great help to the young medical officer who may have to make decisions quickly and alone. The last and largest section of the book lists in alphabetical order many poisonous and potentially poisonous agents. Help with diagnosis and treatment for specific situations is readily available here. The compact book also contains information about the Poison Service in the U.K. and a useful appendix relating to the slang of addicts.

R. R. WATKIN, Guy's Hospital, London SE1 9RT

\section{Diagnosis and Management of Renal and Urinary Diseases. Diagnosis and Management Series}

By J. Michael Boulton-Jones, J. Douglas Briggs and Timothy B. Hargreave. Pp. vii +309 , illustrated. Blackwell Scientific Publications, Oxford, London Edinburgh, Boston, Melbourne, 1982. $£ 10.50$.

This book sets out to provide a concise account of the clinical features and management of disorders of the kidney and urinary tract. It is aimed at clinicians working in or out of hospitals and at the MRCP candidate.

The subject is divided into 20 chapters dealing with anatomy and physiology, urinary tract investigations, primary renal disorders and the kidney in systemic diseases, renal failure and renal replacement therapy. The last seven chapters provide a useful synopsis of urological disorders and their management. Each chapter concludes with a list of points of emphasis.

In a book of such wide scope and small size, the authors need to be dogmatic and although their opinions are usually well-placed there are inevitably a few points of view with which other nephrologists would disagree. For example, it is not true to say that membranous nephropathy does not recur in transplanted kidneys.

The Scottish origin of the book is betrayed by the expression 'outwith this range' but the selection criteria for dialysis which follow reflect the generally gloomy provision throughout the U.K. and would not be accepted in most other Western countries.

There are few important omissions, although it is surprising to see no mention of casts in a detailed section on examination and microscopy of urine.

Some references for further reading would have been valuable, especially in the chapters on physiology, glomerulopathies and drugs.

On the whole it can be said that the authors have achieved their objectives. This is a readable book providing a comprehensive introduction to clinical aspects of renal and urinary tract disorders. There is an excellent chapter on chronic renal failure and the chapter on primary glomerulopathies provides a helpful outline of an often confusing subject. This book can be warmly recommended to candidates revising for higher examinations and provides a useful background for the practising general physician and even the embryo specialist.

B. H. B. ROBINSON, East Birmingham Hospital, Birmingham B9 5ST.

\section{Pediatrics}

Edited by Harold M. Maurer. Pp. xvii +1077 , illustrated Churchill Livingstone, New York, Edinburgh, London and Melbourne, 1983. $£ 28.00$.

This new textbook of paediatrics is modestly designated as intermediate' in size by its editor but nevertheless runs to over 1,000 pages. In common with many comparable editions it is a multiply authored work of which all but five of the $\mathbf{4 9}$ contributors are affiliated to the Commonwealth University in Richmond, Virginia. It is intended to focus on important and common problems for the medical student, house officer and practitioner (in the American sense). The list of chapters is comprehensive with sections on the disorders of each major system. In keeping with the present day concept of the subject, whole chapters are also devoted to adolescent health, primary care, social and emotional problems and the prevention of injury. The book is completed by three useful sections on paediatric radiology, drug therapy and normal laboratory values. The text is reasonably well written, fully illustrated with figures and diagrams and referenced with commendably short lists at the end of each chapter. There are however some irritating features. Is it really logical to consider the whole of growth and development before the newly born? How many paediatricians really consider acute glaucoma, Caffey's disease and scurvy in the differential diagnosis of infantile colic? Moreover, should paediatric dermatology, although extremely well-written and illustrated, command 117 pages when the whole of paediatric surgery is dismissed in 30 ? Why is there such extensive cover of Group A streptococcal disease whereas Group B is scarcely mentioned in the text and not at all in the index.

It is difficult to believe that this book will prove to be a serious rival for the larger more comprehensive texts intended for the aspiring or practising paediatrician. It does however provide a readable and comprehensive overview of the subject for those who require something more than is offered by the short, cryptic handbook. It is therefore commended to medical graduates in disciplines other than paediatrics, medical students and nurses as a useful addition to their personal or institutional libraries.

D. BARLTROP,

Westminster Children's Hospital, London SW1P 2NS

\section{Postgraduate Medicine}

By I. J. T. Davies. 4th edn. Pp. $x+563$, illustrated. Lloyd-Luke (Medical Books) Ltd., London, 1983. £17.00.

There is no doubt that this is an extremely useful and relatively cheap book. The intentions of authors do not always match up with needs of readers, but the ambitious aim to provide a readable text book has, I think, been achieved. I have used it to revise and update subjects in which I am rusty and have scrutinised areas which I think I know something about. I cannot judge the former, but with regard to the latter I think fair and balanced presentations are given. Perhaps it does not work for the small print requirements of jobbing physicians: I could not find anything on orf which we occasionally see in Devon and there was nothing on hyperostosis frontalis interna-a common and ill-understood condition. To be fair, Cecil's textbook did not deal with these diseases either! Both I and my 